TITLE:

\title{
Increased visceral fat mass and insulin signaling in colitis-related colon carcinogenesis model mice
}

$\operatorname{AUTHOR}(\mathrm{S})$ :

Miyamoto, Shingo; Tanaka, Takuji; Murakami, Akira

\section{CITATION:}

Miyamoto, Shingo ... [et al]. Increased visceral fat mass and insulin signaling in colitisrelated colon carcinogenesis model mice. Chemico-Biological Interactions 2010, 183(2): 271-275

ISSUE DATE:

2010-01

URL:

http://hdl.handle.net/2433/91255

\section{RIGHT:}

c 2009 Elsevier Ireland Ltd. All rights reserved.; This is not the published version. Please cite only the published version.; この論文は出版社版で ありません。引用の際には出版社版をご確認ご利用ください。 
1 Increased visceral fat mass and insulin signaling in colitis-related colon

2 carcinogenesis model mice

3

4 Shingo Miyamoto ${ }^{a}$, Takuji Tanaka ${ }^{\text {, }}$, and Akira Murakami, ${ }^{\mathrm{a}, *}$

5

$6{ }^{a}$ Division of Food Science and Biotechnology, Graduate School of Agriculture,

7 Kyoto University, Kyoto 606-8502, Japan

8 bepartment of Oncologic Pathology, Kanazawa Medical University, 1-1 Daigaku,

9 Uchinada, Ishikawa 920-0293, Japan

10 *Corresponding author. Fax: +81-75-753-6284; E-mail: cancer@kais.kyoto-u.ac.jp

13 Abbreviations: Akt, protein kinase B; AOM, azoxymethane; CD, Crohn's disease;

14 CRC, colorectal cancer; DSS, dextran sulfate sodium; ERK, extracellular

15 signal-regulated protein kinase; IBD, inflammatory bowel disease; IL-6, interleukin-6;

16 mTOR, mammalian target of rapamycin; Ob-R, leptin receptor; TNF- $\alpha$, tumor necrosis

17 factor- $\alpha$ 
Miyamoto 2

\section{Abstract}

2

3 Leptin, a pleiotropic hormone regulating food intake and metabolism, plays an 4 important role in the regulation of inflammation and immunity. We previously

5 demonstrated that serum leptin levels are profoundly increased in mice which received 6 azoxymethane (AOM) and dextran sulfate sodium (DSS) as tumor-initiator and 7 -promoter, respectively, in a colon carcinogenesis model. In this study, we attempted to

8 address underlying mechanism whereby leptin is up-regulated in this rodent model.

9 Five-week-old male ICR mice were given a single intraperitoneal injection of AOM 10 (week 0), followed by 1\% DSS in drinking water for 7 days. Thereafter, the weights of 11 visceral fats and the serum concentration of leptin were determined at week 20 . Of 12 interest, the relative epididymal fat pad and mesenteric fat weights, together with serum 13 leptin levels in the AOM and/or DSS-treated mice were markedly increased compared 14 to that in untreated mice. In addition, leptin protein production in epididymal fat pad 15 with AOM/DSS-treated mice was 4.7-fold higher than that of control. Further, insulin 16 signaling molecules, such as protein kinase B (Akt), S6, mitogen-activate protein 17 kinase/ extracellular signaling-regulated kinase 1/2, and extracellular signaling18 regulated kinase 1/2, were concomitantly activated in epididymal fat of AOM/DSStreated mice. This treatment also increased the serum insulin and IGF-1 levels. Taken together, our results suggest that higher levels of serum insulin and IGF-1 promote the

21 insulin signaling in epididymal fat and thereby increasing serum leptin, which may play

22 an crucial role in, not only obesity-related, but also -independent colon carcinogenesis.

24 Key words: leptin, colon carcinogenesis, epididymal fat pad, insulin signaling 
Miyamoto 3

\section{Introduction}

2

4 shown to be a regulator of body weight and energy balance, functioning in the

5 hypothalamus [1]. Although this hormone is produced mainly by WAT, its expression

6 has also been detected in other tissues, including the gastrointestinal tract [2]. In humans,

7 leptin levels are proportional to body mass index and are elevated in obese individuals

8 [3]. Since obesity is known to increase the risk of certain cancers, great effort has been

9 directed to elucidating the possible role of leptin in cancer development [4], and several

10 in vitro studies showed that leptin can act as a mitogenic, anti-apoptotic, and

11 tumorigenic factor with various cancer cell lines [5-7]. In addition, data obtained with

12 clinical samples revealed that leptin and its receptor (Ob-R) are expressed in cancer

13 tissues [8]. Thus, the leptin system might promote cancer progression in an autocrine

14 and paracrine manner.

15 Our previous investigation demonstrated that serum leptin levels were profoundly 16 increased in male ICR mice that received azoxymethane (AOM) and dextran sulfate 17 sodium (DSS) for colitis-related colon carcinogenesis [9]. In addition, a citrus flavonoid, 18 nobiletin, reduced not only those levels, but also colonic tumor development, whereas 19 did not cause significant alterationsin serum levels of other adipocytokines (TNF- $\alpha$, 20 IL-6, and adiponectin) and triglyceride [9]. These findings led us to address and 21 investigate an issue why and how serum leptin level is elevated in the mice treated with 22 AOM and DSS in a colitis-related colon carcinogenesis model. 
Miyamoto 4

2 Animals and chemicals

3 Male Crj:CD-1 (ICR) mice (Japan SLC, Shizuoka, Japan) aged 5 weeks were

4 obtained for this study. The animals were handled according to the Guidelines for the

5 Regulation of Animals provided by the Experimentation Committee of Kyoto

6 University and the experimental protocol was approved by the Committee. Upon arrival,

7 all mice were randomized and transferred to plastic cages (5 mice/cage), with free

8 access to drinking water and a pelleted basal diet MF diet (Oriental Yeast, Kyoto, Japan),

9 and controlled conditions of humidity (60 \pm 5\%), light (12/12-hour light/dark cycle) and

10 temperature $\left(24 \pm 2^{\circ} \mathrm{C}\right)$. All mice were quarantined for 1 week before starting the

11 experiments.

12 The colonic carcinogen AOM was purchased from Sigma Chemical Co. (St. Louis, 13 MO). DSS with a molecular weight of 36,000 to 50,000 (Cat. No. 160110) was

14 purchased from the MP Biochemicals, LLC (Aurora, OH) and used for induction of 15 colitis, after being dissolved in distilled water to a concentration of $1 \%(w / v)$.

17 Antibodies

18 Antibodies directed against phospho-protein kinase B (Akt) (Ser483), phospho-S6

19 (Ser240/244), phospho-mitogen-activate protein kinase/ extracellular signaling-regulated kinase (MEK)1/2 (Ser217/221) and phospho- extracellular

21 signaling-regulated kinase (ERK)1/2 (Thr202/Tyr204), as well as horseradish

22 peroxidase (HRP)-conjugated anti-rabbit antibody were obtained from Cell Signaling

23 Technology (Beverly, MA). 
Miyamoto 5

1

2

\section{Animal treatment}

A total of 80 male ICR mice were divided into four (3 experimental and 1 control) groups. Group 1 served as an untreated control. Mice in groups 2 and 4 were given a single i.p. injection of AOM (10 mg/kg body weight), then starting 1 week after that injection, those in group 4 received 1\% DSS in drinking water for 7 days. Mice on group 3 received DSS alone according to the same time schedule. All groups were fed the basal diet throughout the study. At the end of weeks 2, 5 mice from each group were euthanized, then 15 mice from each group were euthanized after week 20. Euthanasia was performed under ether anesthesia, then blood samples were collected from the abdominal aorta. During the study, body weights of all animals were weighted weekly. At sacrifice, all organs, including adipose tissue, were removed and weighted, and then obtained adipose tissues were frozen using liquid nitrogen, until later use.

\section{Reverse transcription-polymerase chain reaction (RT-PCR)}

Total RNA was extracted from the epididymal fat pads using TRIzol reagent (Invitrogen, Carlsbad, CA), according to the manufacturer's instructions. cDNA was synthesized using $1 \mu \mathrm{g}$ of total RNA with an RNA PCR Kit (AMV). PCR amplification was performed using a thermal cycler (PTC-100TM, MJ Research, Watertown, MA) and conducted with each sense and antisense primer, with GAPDH used as the internal standard. The primers for leptin were 5'-CCAAAACCCTCATCAAGACC-3' and 5'GTCCAACTGTTGAAGAATGTCCC-3’ (Proligo, Kyoto, Japan), which yielded an expected band size of 395 bp, while those for GAPDH were 5'-GTGAAGGTCGGAGTCAACG-3' and 5’-GGTGAAGACGCCAGTGGACTC-3’' (Proligo), which yielded an expected band size of $300 \mathrm{bp}$. The primers were used at final concentrations of 0.5 
Miyamoto 6

1 and $0.05 \mu \mathrm{M}$ respectively. PCR was performed under the following conditions: 43

2 cycles at $95^{\circ} \mathrm{C}$ for 45 seconds, $57^{\circ} \mathrm{C}$ for 45 seconds, and $72^{\circ} \mathrm{C}$ for 45 seconds for leptin,

3 and 27 cycles at $94^{\circ} \mathrm{C}$ for 30 seconds, $55^{\circ} \mathrm{C}$ for 30 seconds, and $72^{\circ} \mathrm{C}$ for 30 seconds for

4 GAPDH. The PCR products were subjected to electrophoresis on 3\% agarose gels and

5 stained with SYBR $^{\mathbb{R}}$ Gold. The intensity of each band was analyzed using Scion

6 Image.

7

$8 \quad$ Western blotting

9 To determine the protein expressions of phospho-Akt, phospho-S6, 10 phospho-MEK1/2, and phospho-ERK1/2 in the epididymal fat pads, tissue supernatants 11 were subjected to Western blotting. Frozen adipose tissue was lysed in lysis buffer [10 $12 \mathrm{nM}$ Tris, $\mathrm{pH}$ 7.4, 1\% sodium dodecyl sulfate (SDS), $1 \mathrm{mM}$ sodium metavanadate (V)], 13 and centrifuged at $3200 \times g$ for 5 minutes. Denatured proteins (40 $\mu$ g) were separated 14 using SDS-PAGE on a $10 \%$ polyacrylamide gel and then transferred to Immobilon-P 15 membranes (Millipore, Billerica, MA). After blocking with Block Ace (Snow Brand 16 Milk Products, Tokyo, Japan) for 1 hour, the membranes were reacted with the 17 corresponding specific primary antibody (1:1000), followed by the corresponding 18 HRP-conjugated secondary antibody (1:1000). The blots were developed using ECL 19 Western blotting detection reagents. The intensity of each band was analyzed using 20 Scion Image.

Clinical chemistry

23 The collected blood samples were used for clinical chemistry measurements of 24 leptin (Quantikine Mouse leptin, ELISA/Assay Kit, R\&D Systems Inc.), insulin (Insulin 
1

$6 \quad$ Statistical analysis

7

8

9

\section{Results}

11

12

13

14

15

measurement kit, Morinaga Institute of Biological Science), and insulin-like growth factor (IGF)-1 (Quantikine Mouse IGF-1, ELISA/Assay Kit, R\&D Systems Inc.). The samples were used without dilution for insulin measurements, while they were diluted 20- and 500-fold for leptin and IGF-1.

Data were analyzed using Student's $t$-test (two-sided) when appropriate, with $P<$ 0.05 considered to indicate significance.

\section{General observations of mice}

Food intake was significantly $(P<0.05)$ lower in group 4 as compared to group 1 (Figure 1A). The mean body weights of mice in groups 2 through 4 are higher than group 1, though the differences did not reach statistical significance (Figure 1B). In addition, the AOM and/or DSS treatment led to notable increases in mean relative epididymal fat pad weight (g/100 g body weight), which was most notable in group 4 (AOM and DSS), as the weight was significantly $(P<0.05)$ increased by 1.7 -fold as compared to group 1 (Figure 1C). However, the mean relative mesenteric fat weight (g/100 g body weight) did not significantly differ among the groups (Figure 1D).

\section{Leptin level in the serum and epididymal fat pad}

As shown in Figure 2, the serum concentration of leptin in group 4 was significantly $(P<0.05)$ elevated by 3.0-fold as compared to group 1 , which is consistent with our 
Miyamoto 8

1 previous findings [9]. The serum leptin levels in groups 2 and 3 were also increased by

2 1.8- and 2.2-fold as compared to group 1, respectively, without statistical significance.

3 Since leptin is produced mainly by WAT, we assessed the level of leptin mRNA and

4 protein expression in epididymal fat pads. Leptin mRNA expression in the mice treated

5 with both AOM and DSS (group 4) was increased by 2.0-fold as compared to the

6 untreated control (Figure 3A), while leptin protein production was also increased by

$7 \quad$ 4.7-fold $(P<0.05)$ in group 4 mice (Figure 3B).

8

9 Activation of insulin signaling pathway in epididymal fat pads

10 Insulin is an important physiological factor that activates mammalian target of 11 rapamycin (mTOR), which is a master regulator of protein synthesis [10], adipose tissue 12 morphogenesis [11], and leptin synthesis/secretion [12] in adipocytes. To determine 13 whether the insulin signaling pathway was activated in the epididymal fat pads of the 14 present ICR mice, we ditermined the phosphorylation status of Akt, S6, MEK1/2, and 15 ERK1/2, all of which are involved in that pathway [13]. As shown in Figure 3, AOM 16 and DSS treatment substantially increased the phosphorylation of Akt (3.5-fold, $P<$ 17 0.05, Figure 3C), S6 (38-fold, $P<0.05$, Figure 3D), MEK (5.4-fold, $P<0.05$, Figure 18 3E), and ERK (8.8-fold, $P<0.05$, Figure 3F), respectively, as compared to the untreated 19 control mice.

Serum levels of insulin and IGF-1

We also assessed the serum levels of insulin and IGF-1 at two time-points, week 2

23 (just after the cessation of the DSS treatment) and 20 (the termination of the study). As

24 shown in Figure 4A, serum insulin was elevated in a time-dependent manner by 2.1- 
Miyamoto 9

1 and 7.8-fold in groups 1 and 4, respectively. Meanwhile, the level of IGF-1 in group 4

2 was significantly $(P<0.05)$ higher at week 20 than that in group 1 , which was in

3 contrast to the findings at week 2 (Figure 4B).

5 Discussion

6

7 Colorectal cancer (CRC) is the most serious complication associated with long

8 standing inflammatory bowel disease (IBD), which includes ulcerative colitis and

9 Crohn's disease (CD) $[14,15]$. Mesenteric WAT is mainly hypertrophic around the

10 intestines in IBD patients, with axial polarity of inflammation the mainstay contributor

11 [16]. To better understand the pathogenesis of IBD-related CRC, one (T.T.) of the

12 present authors and colleagues developed a novel colitis-related CRC model (a

13 two-stage mouse colon carcinogenesis model), which were initiated with AOM and

14 promoted by DSS [17]. In the current study, such sequential treatment significantly

15 increased serum leptin and epididymal fat pad weight, whereas mesenteric fat was not

16 altered (Figure 1C and D). The individual potencies were less than their combination,

17 suggesting that AOM and DSS act additively to increase the concentration of leptin in 18 serum.

19 Bendet et al. reported that insulin secretion during a 3-hour oral glucose-tolerance test was increased and homeostatic model assessment values were decreased in CD

21 patients [18]. In a later study, Bregenzer et al. found increased insulin resistance and $\beta$

22 cell function in CD patients [19]. Furthermore, it should be noted that the concentration

23 of serum C-peptide, a stable indicator of steady-state insulin secretion, was reported to

24 be higher in AOM-treated male rats [20]. Since insulin resistance increases the level of 
Miyamoto 10

1 serum IGF-1 [21], the increased level of IGF-1 in serum of the present group 4 mice

2 (Figure 4B) may have been associated with putative insulin resistance caused by

3 AOM/DSS-induced inflammation with other pathologic conditions, including oxidative

4 stress.

5 Under physiological conditions, serum leptin levels are affected by several factors,

6 and leptin secretion from adipocytes is dominantly dependent on the status of adipocyte

7 signaling molecules. A previous study showed that both insulin and IGF-1 have been

8 reported to be important physiological factors activating mTOR. Activation of this

9 pathway mediates multiple insulin effects, such as stimulation of adipogenesis or

10 lipogenesis [22], and potentiation of leptin secretion. In the present study, the

11 insulin/IGF signaling pathway was consistently activated, and leptin induction and

12 production were promoted in the epididymal fat of mice treated with AOM and DSS

13 (Figure 3A-F). Thus, it is suggested that these hormones stimulate growth and

14 differentiation of visceral fat tissue, thereby accelerating leptin production.

15 In conclusion, we found that higher levels of serum insulin and IGF-1 promote

16 insulin signaling in epididymal fat, which may lead to increased amounts of visceral fat

17 tissue and a resulting elevation of serum leptin. These events may play certain critical

18 roles in the development of CRC. However, further studies are warranted for

19 understanding the precise mechanisms underlying AOM and DSS-induced adipose

20 tissue alterations.

Acknowledgements 
Miyamoto 11

1 Ministry of Health, Labor and Welfare of Japan (A.M. and T.T.), a Grant-in Aid for

2 Scientific Research (C) (A.M.), and the Japan Society for the Promotion of Science 3 Fellows (S.M.).

4 
Miyamoto 12

\section{References}

2

3 [1] Y. Zhang, R. Proenca, M. Maffei, M. Barone, L. Leopold, J. Friedman,

4 Positional cloning of the mouse obese gene and its human homologue., Nature 5 372(6505) (1994) 425-432.

6 [2] S. Sitaraman, X. Liu, L. Charrier, L. Gu, T. Ziegler, A. Gewirtz, D. Merlin, 7 Colonic leptin: source of a novel proinflammatory cytokine involved in IBD., FASEB J 8 18(6) (2004) 696-698.

9 [3] J. Kolaczynski, J. Ohannesian, R. Considine, C. Marco, J. Caro, Response of 10 leptin to short-term and prolonged overfeeding in humans., J Clin Endocrinol Metab 11 81(11) (1996) 4162-4165.

12 [4] C. Garofalo, E. Surmacz, Leptin and cancer., J Cell Physiol 207(1) (2006) $13 \quad 12-22$.

14 [5] J. Hardwick, G. Van Den Brink, G. Offerhaus, S. Van Deventer, M. 15 Peppelenbosch, Leptin is a growth factor for colonic epithelial cells., Gastroenterology 16 121(1) (2001) 79-90.

17 [6] P. Rouet-Benzineb, T. Aparicio, S. Guilmeau, C. Pouzet, V. Descatoire, M. 18 Buyse, A. Bado, Leptin counteracts sodium butyrate-induced apoptosis in human colon 19 cancer HT-29 cells via NF-kappaB signaling., J Biol Chem 279(16) (2004) $20 \quad 16495-16502$.

21 [7] O. Ogunwobi, I. Beales, The anti-apoptotic and growth stimulatory actions of 22 leptin in human colon cancer cells involves activation of JNK mitogen activated protein 23 kinase, JAK2 and PI3 kinase/Akt., Int J Colorectal Dis 22(4) (2007) 401-409.

24 [8] M. Koda, M. Sulkowska, L. Kanczuga-Koda, E. Surmacz, S. Sulkowski, 25 Overexpression of the obesity hormone leptin in human colorectal cancer., J Clin Pathol 26 60(8) (2007) 902-906.

27 [9] S. Miyamoto, Y. Yasui, T. Tanaka, H. Ohigashi, A. Murakami, Suppressive 28 effects of nobiletin on hyperleptinemia and colitis-related colon carcinogenesis in male 29 ICR mice., Carcinogenesis 29(5) (2008) 1057-1063.

30 [10] C. Lynch, B. Patson, J. Anthony, A. Vaval, L. Jefferson, T. Vary, Leucine is a 31 direct-acting nutrient signal that regulates protein synthesis in adipose tissue., Am J 32 Physiol Endocrinol Metab 283(3) (2002) E503-513.

33 [11] H. Fox, S. Kimball, L. Jefferson, C. Lynch, Amino acids stimulate 34 phosphorylation of p70S6k and organization of rat adipocytes into multicellular 35 clusters., Am J Physiol 274(1 Pt 1) (1998) C206-213.

36 [12] C. Roh, J. Han, A. Tzatsos, K. Kandror, Nutrient-sensing mTOR-mediated 
1 pathway regulates leptin production in isolated rat adipocytes., Am J Physiol Endocrinol 2 Metab 284(2) (2003) E322-330.

3 [13] R. Bradley, B. Cheatham, Regulation of ob gene expression and leptin 4 secretion by insulin and dexamethasone in rat adipocytes., Diabetes 48(2) (1999) $5 \quad 272-278$.

6 [14] J. Eaden, K. Abrams, J. Mayberry, The risk of colorectal cancer in ulcerative 7 colitis: a meta-analysis., Gut 48(4) (2001) 526-535.

8 [15] R. van Hogezand, R. Eichhorn, A. Choudry, R. Veenendaal, C. Lamers, 9 Malignancies in inflammatory bowel disease: fact or fiction?, Scand J Gastroenterol 10 Suppl(236) (2002) 48-53.

11 [16] K. Karmiris, I. Koutroubakis, E. Kouroumalis, Leptin, adiponectin, resistin, 12 and ghrelin--implications for inflammatory bowel disease., Mol Nutr Food Res 52(8) 13 (2008) 855-866.

14 [17] T. Tanaka, H. Kohno, R. Suzuki, Y. Yamada, S. Sugie, H. Mori, A novel 15 inflammation-related mouse colon carcinogenesis model induced by azoxymethane and 16 dextran sodium sulfate., Cancer Sci 94(11) (2003) 965-973.

17 [18] N. Bendet, E. Scapa, O. Cohen, O. Bloch, D. Aharoni, Y. Ramot, M. Weiss, A. 18 Halevi, M. Rapoport, Enhanced glucose-dependent glucagon-like peptide-1 and insulin 19 secretion in Crohn patients with terminal ileum disease is unrelated to disease activity or 20 ileal resection., Scand J Gastroenterol 39(7) (2004) 650-656.

21 [19] N. Bregenzer, A. Hartmann, U. Strauch, J. Schölmerich, T. Andus, L. 22 Bollheimer, Increased insulin resistance and beta cell activity in patients with Crohn's 23 disease., Inflamm Bowel Dis 12(1) (2006) 53-56.

24 [20] R. Xiao, J. Carter, A. Linz, M. Ferguson, T. Badger, F. Simmen, Dietary whey 25 protein lowers serum C-peptide concentration and duodenal SREBP-1c mRNA 26 abundance, and reduces occurrence of duodenal tumors and colon aberrant crypt foci in 27 azoxymethane-treated male rats., J Nutr Biochem 17(9) (2006) 626-634.

28 [21] E. Giovannucci, Nutrition, insulin, insulin-like growth factors and cancer., 29 Horm Metab Res 35(11-12) (2003) 694-704.

30 [22] H. Cho, J. Park, H. Lee, Y. Lee, J. Kim, Regulation of adipocyte differentiation 31 and insulin action with rapamycin., Biochem Biophys Res Commun 321(4) (2004) 32 942-948. 
Miyamoto 14

\section{$1 \quad$ Figure legends}

2

3 Figure 1 . The mean food intake (A) by the mice during the study, body (B), epididymal fat pad (C), and mesenteric fat (D) weights. The weights were measured at the end of the study.

Figure 2. Serum leptin levels of all groups. The levels were quantified by ELISA, as described in Materials and Methods. Each values is shown as the mean $\pm \mathrm{SD}$ $(\mathrm{n}=15)$. Statistical analysis was performed using Student's $t$-test: $* P<0.05$ vs. the untreated control (group 1).

Figure 3. Leptin production and activation of insulin signaling pathway in epididymal fat pads at the end of the study. (A) Leptin mRNA expression was determined by RT-PCR, as described in Materials and Methods, with the levels corrected by those of GAPDH. Each values is shown as the mean \pm SD $(n=5)$, with 3 representative results presented. (B) Leptin protein amounts were quantified by ELISA, as described in Materials and Methods. Each values is shown as the mean \pm SD $(n=10)$. (C-F) Activation of the insulin signaling pathway was examined by Western blotting, as described in Materials and Methods. Each values is shown as the mean $\pm \operatorname{SD}(n=10)$, with 3 representative results presented. Statistical analysis was performed using Student's $t$-test: $* P<0.05$ vs. the untretated control (group 1).

24 Figure 4. Levels of serum insulin (A) and IGF-1 (B) after weeks 2 and 20. Serum 
insulin and IGF-1 levels were quantified by ELISA, as described in Materials and Methods. Open bars; at week 2, closed bars; at week 20. Each values is shown as the mean \pm SD ( $n=5$ or 15 ). Statistical analysis was performed using Student's t-test: $* P<0.05$ vs. the untreated control (group 1) for the corresponding time point. 
A

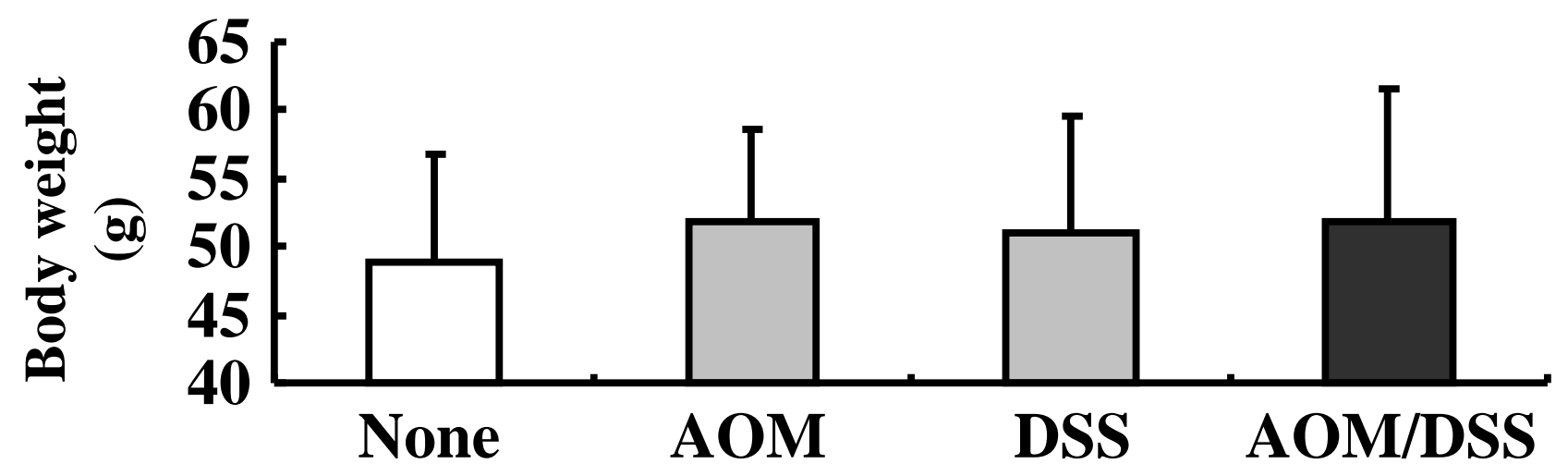

B
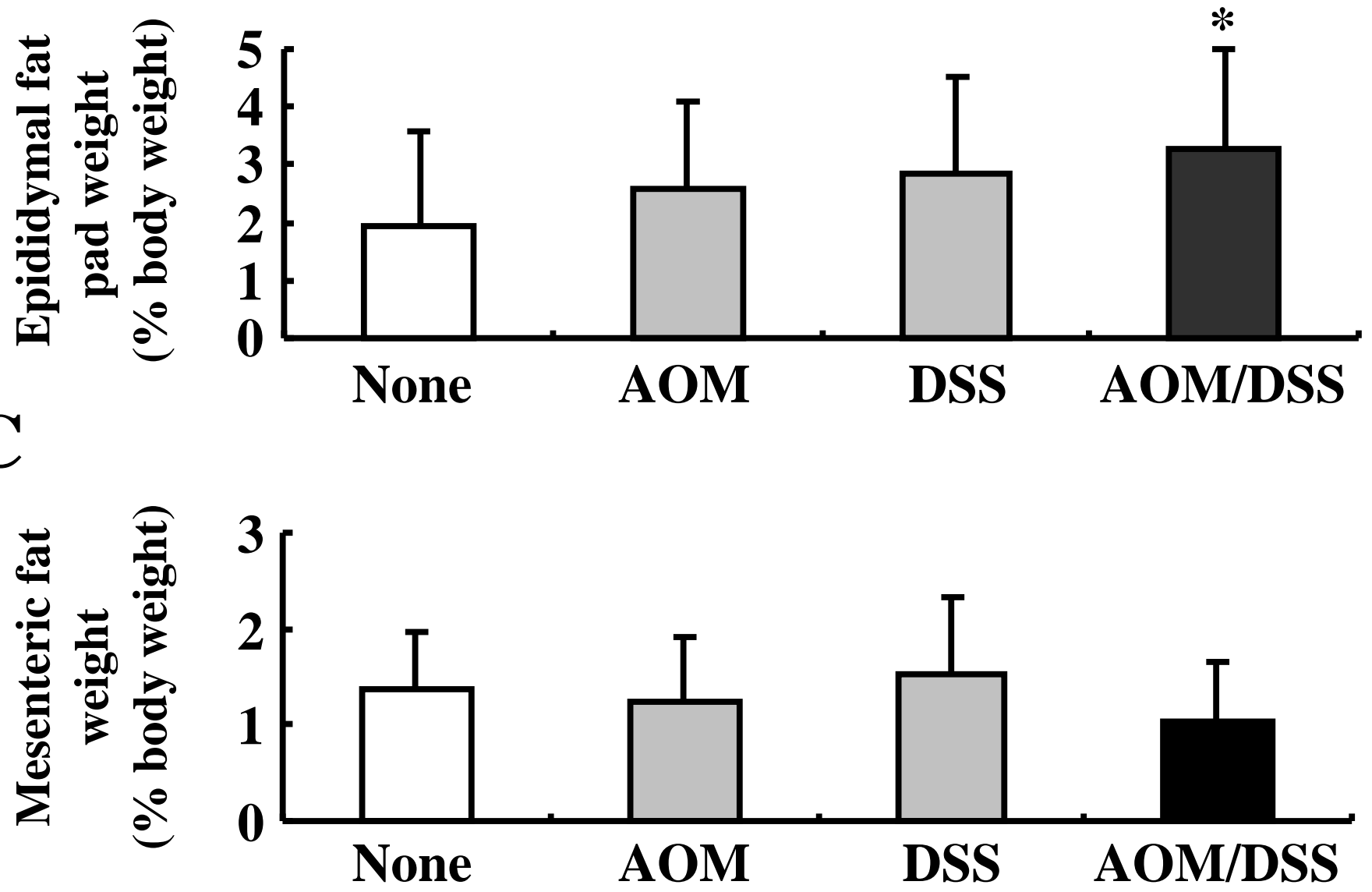

D

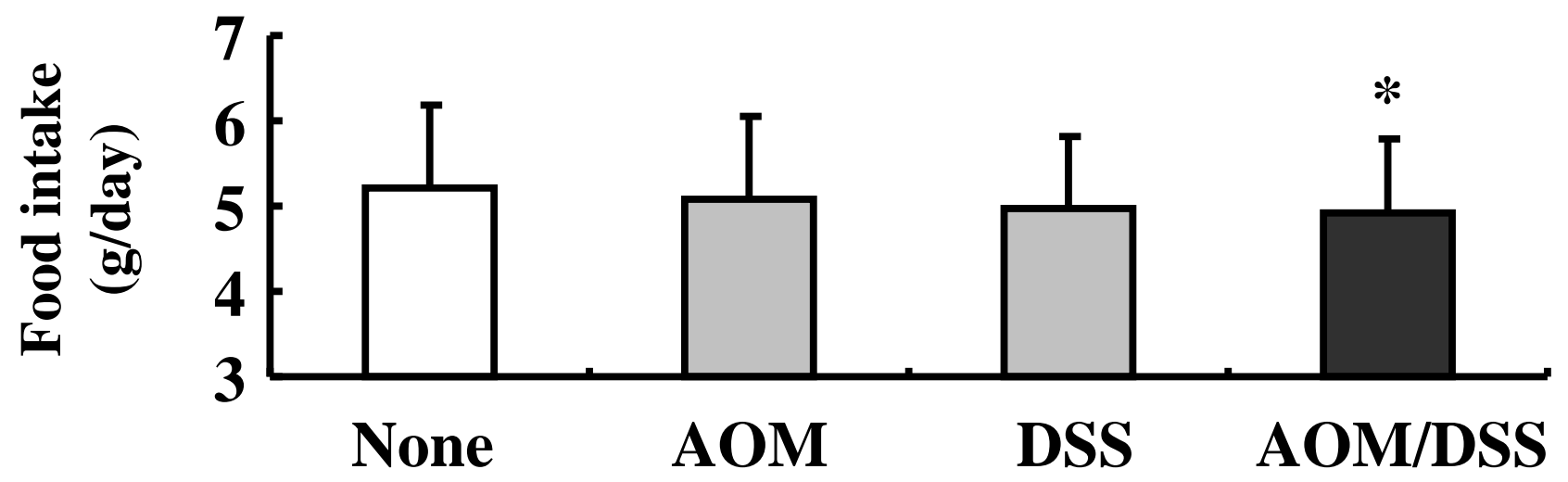


Fig. 2 (Miyamoto et al.)

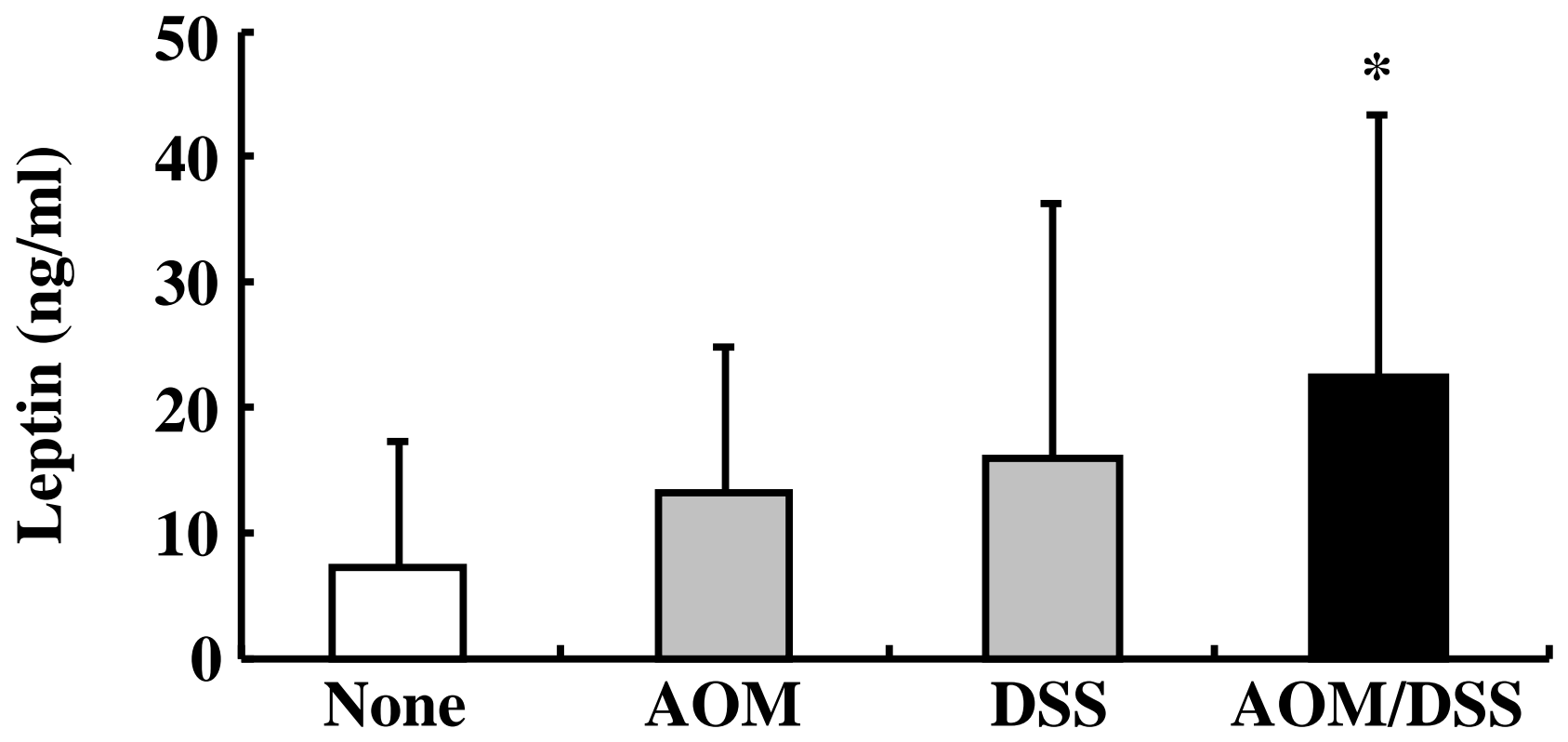


A

B

$\frac{\pi}{2}$

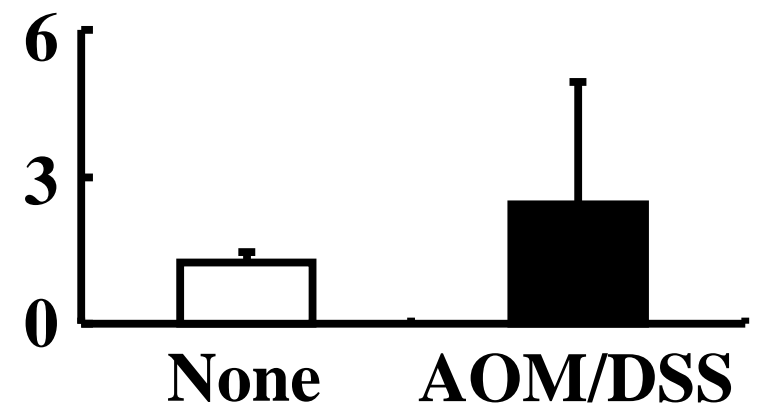

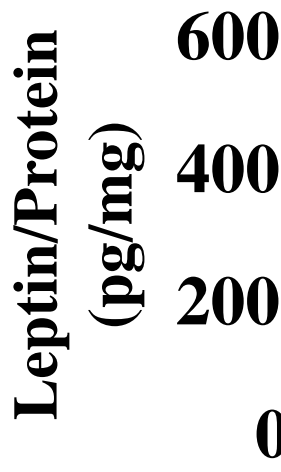

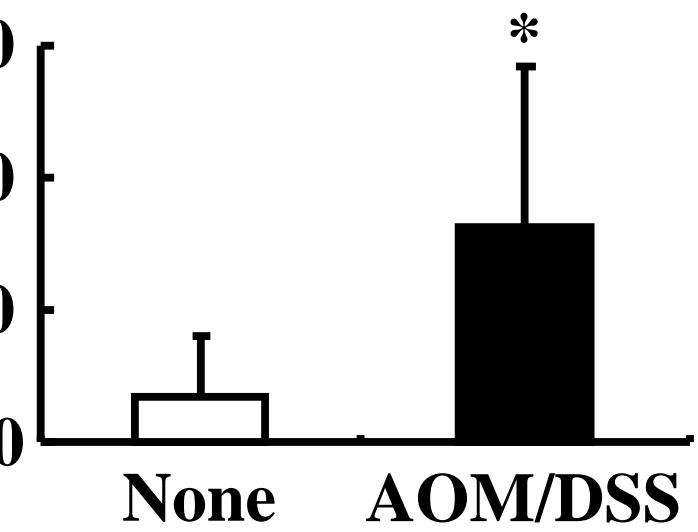

$C$

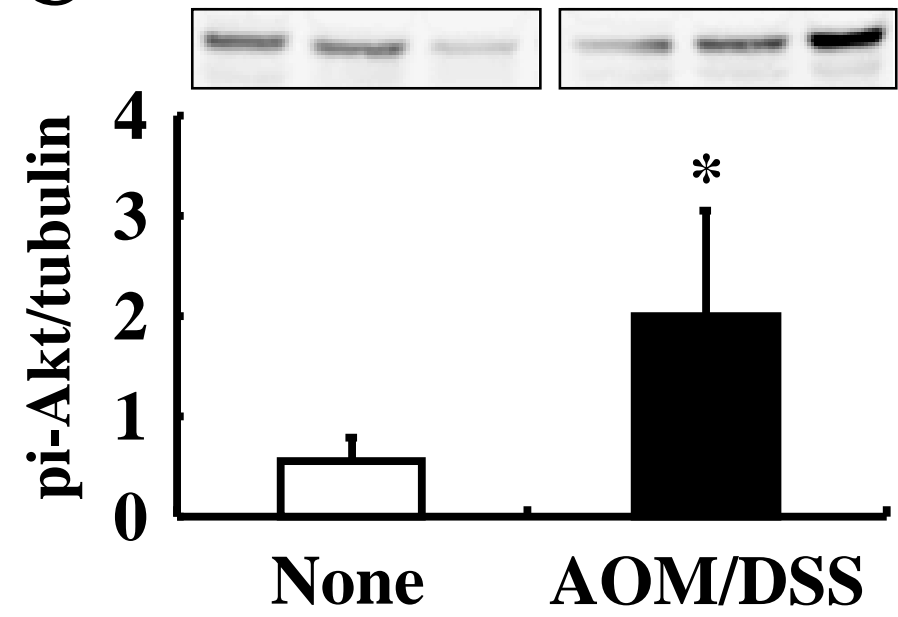

D

E
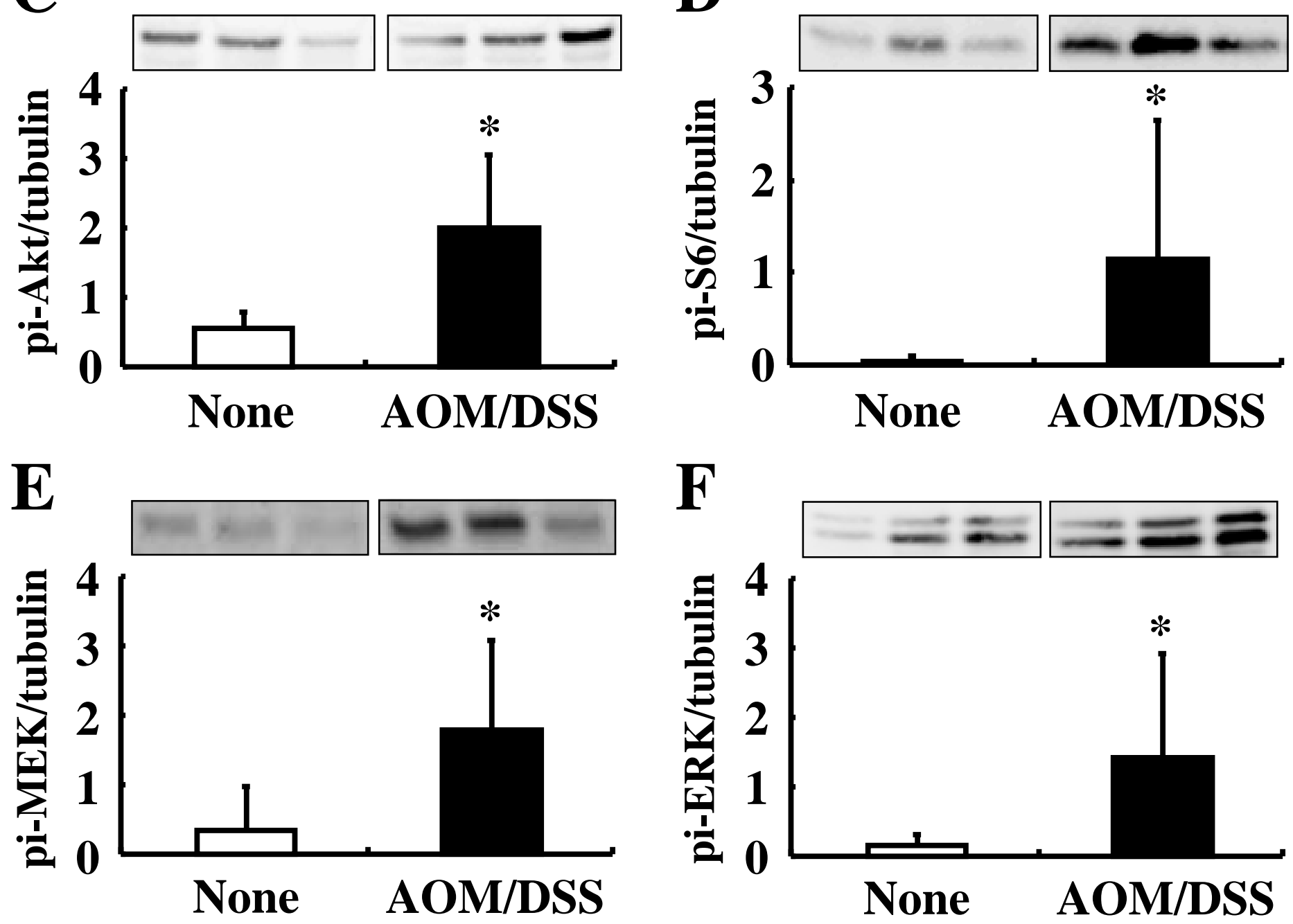

$\mathbf{F}$

None AOM/DSS

None

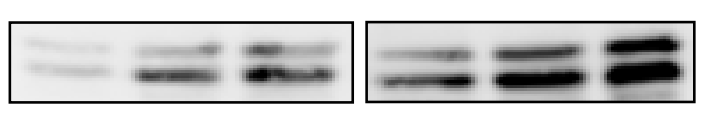

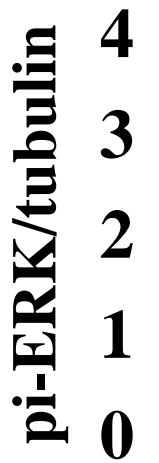

None AOM/DSS

\section{AOM/DSS}


A

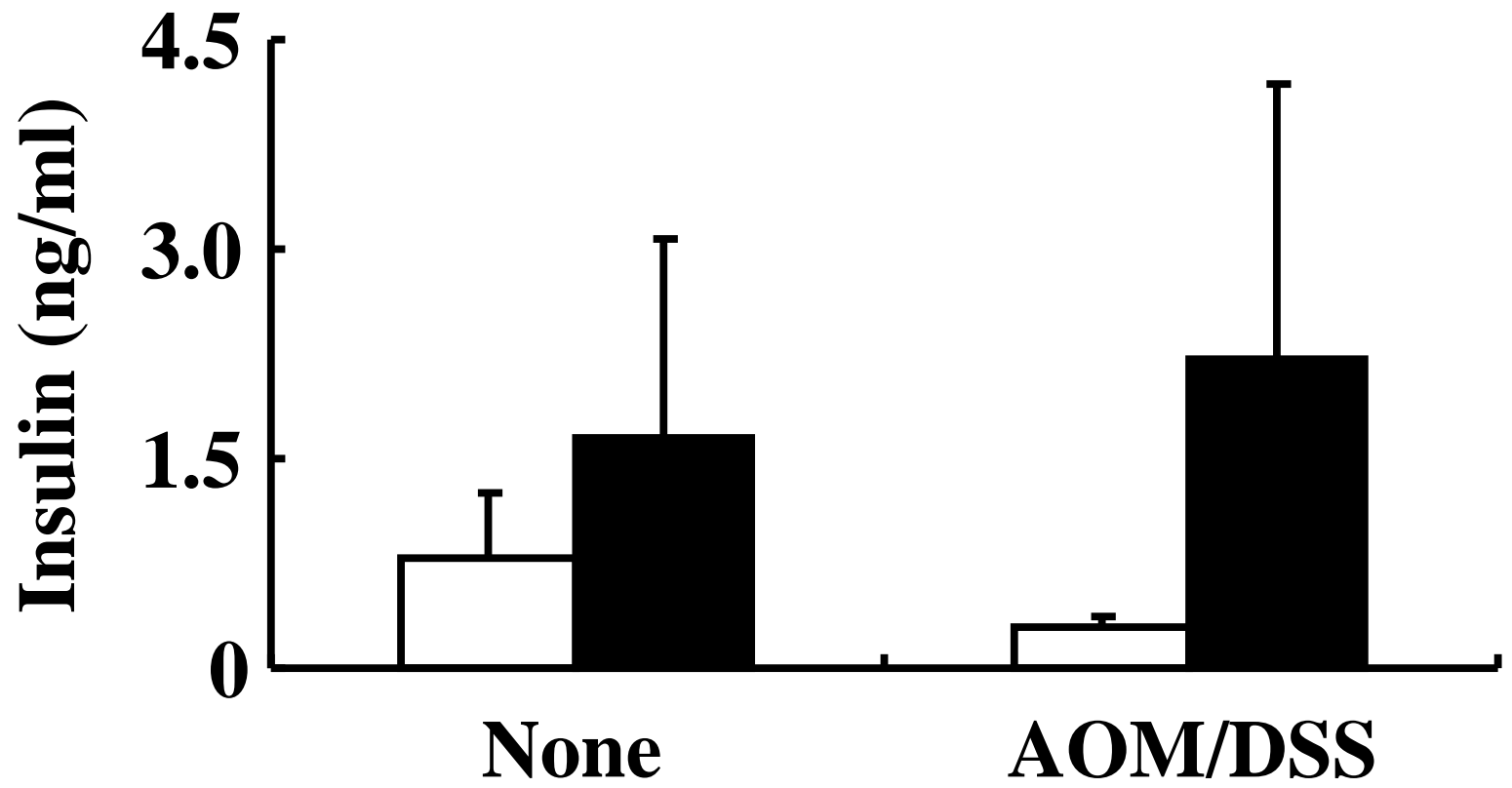

B

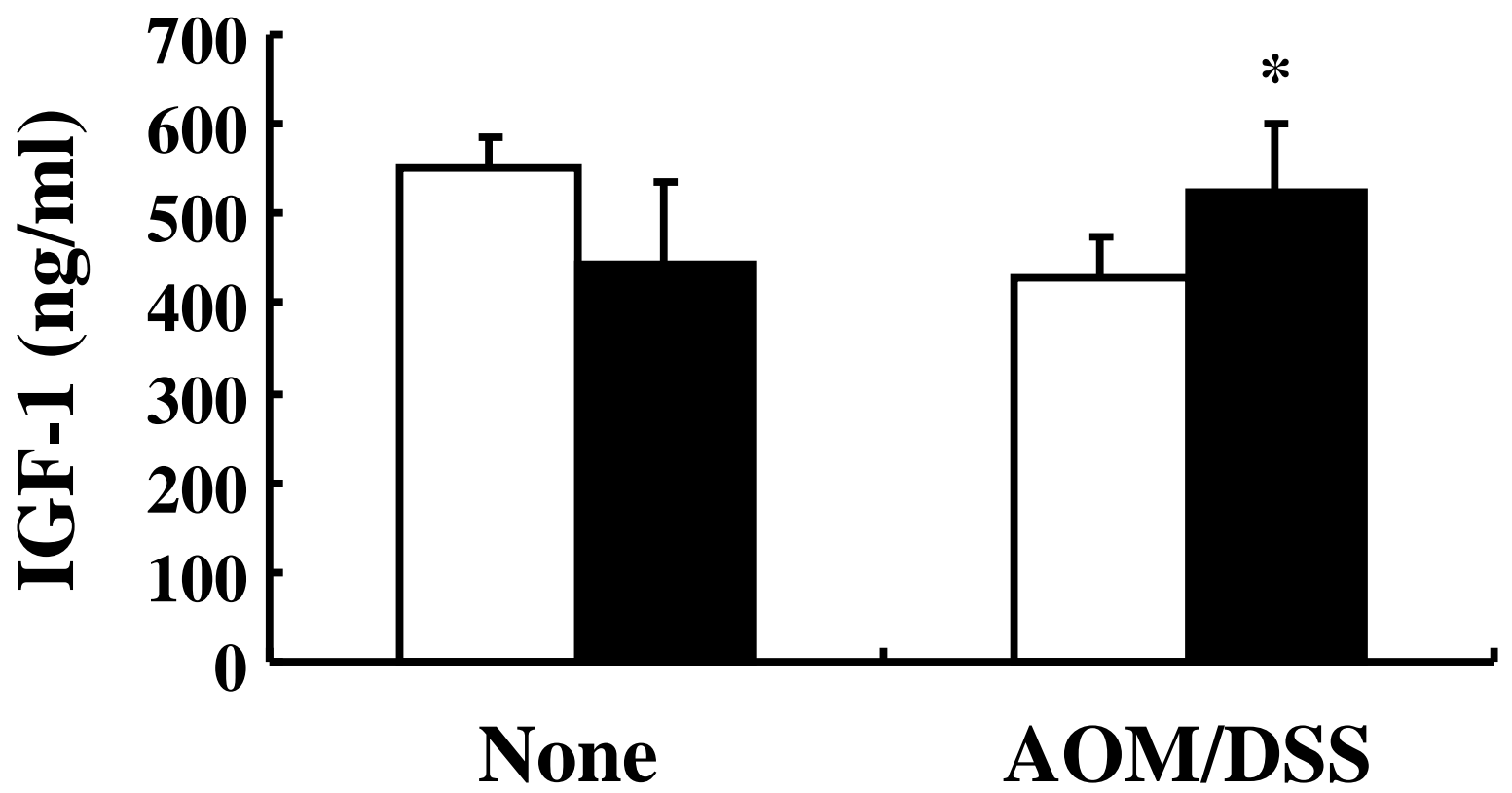

